\title{
Transferring ELT Knowledge to the Classroom - Results of a Study
}

ABSTRACT. The author has been struggling with problems, the most worrying of which ahs always been the students' inability to transfer the knowledge and skills they should have acquired during the course to the English language classroom. In an attempt to find out the possible reasons for such a situation the author made a small-scale survey, the results of which are presented below.

\section{INTRODUCTION}

The author of the present article has been teaching ELT methodology at the School of English A. Mickiewicz University for six years. During this period, she has been able to draw a number of conclusions from her teaching that, hopefully, have made courses more interesting, relevant, and useful for her students. However, she has also been struggling with problems, the most worrying of which has always been the students' inability to tra ns fer the knowledge and skills they should have acquired during the course to the English language classroom. In an attempt to find out the possible reasons for such a situation the author made a small-scale survey, the results of which are presented below.

\section{ELT METHODOLOGY AT THE SCHOOL OF ENGLISH ADAM MICKIEWICZ UNIVERSITY}

Prior to 2001, ELT methodology in the form of lectures and classes was taught for two semesters in the third year. While the lectures were held for all students together and delivered by a single professor, the classes were run by a number of teachers and the students attended them in groups of up 
to 16 people. After completing the course in May, the students then did a 150 -hour teacher training practice in September in a primary or secondary school they themselves selected. From among the methodology teachers, one was responsible for overseeing the whole business, i.e. filling in all the necessary documents for the students and the school authorities, checking the trainees' diaries (containing the topics of the lessons they did, comments of the supervising teacher at the school, etc.), as well as visiting the students teaching in the schools. Obviously, dealing with about a hundred trainees each year, the teacher in charge had very little control over an average student, whereas the other methodology teachers had nothing to do with their students' teaching practice at all.

The situation changed in 2001 with the introduction of BA studies and a program that would be compatible with the European Union standards. Now ELT methodology begins in the second semester of the second year and lasts three semesters. As before, once a week the students attend a twohour lecture (which covers more theoretical issues like first and second language acquisition theories, teacher and learner factors, approaches to and methods of language teaching, etc.) and a two-hour class by and large devoted to the te chniques of teaching language skills (e.g. reading, speaking) and components (e.g. grammar, vocabulary), classroom management, teaching aids, etc. Simultaneously, the students go to schools, where they first observe foreign language lessons (for about 100 hours) and then teach English themselves (50 hours). Thanks to these changes, the methodology teachers not only gained extra class time but also the necessary control over their students' teacher training practice. Each teacher is now responsible for his/her trainees and is required to visit and observe every student at work at least once. In this way, the trainer is able to evaluate his/her students' teaching skills not only during the somewhat artificial micro-teaching tasks in the methodology classes, but in the genuine school context as well. And it is primarily the visits to schools that have made the author realize how little of what the trainees learn in class is actually used while teaching.

\section{THE TRAINEES' MAJOR PROBLEMS}

Because the trainees begin teaching English at schools while the methodology course is still in progress, they often experience difficulties and make mistakes when trying to tackle the skill or component that has not been thoroughly covered yet. Besides, like any novice instructors, they struggle with discipline and classroom management generally. While the above problems are completely understandable, it is hard to comprehend why, once they enter the school classroom, the students seem to forget most of the principles of language teaching they are well familiar with. 
The problems the trainees have or the areas within which they make most mistakes can be divided into global (referring to the trainees' attitudes and beliefs about teaching and learning) and specific (related to teaching particular language skills and components). Because the latter will frequently stem from the former, the global problems will be described in more detail, whereas specific problems will be illustrated with selected examples.

\subsection{Global problems}

Although the researcher is a great supporter of the direct approach (i.e. no L1, or at least very little, in classroom) to foreign language teaching and as such from the very beginning of the methodology course she tries to instill the same attitude in her students, the lessons she visits are basically run in the learners' native language. They generally resemble grammar-translation lessons with the teacher and learners talking about the foreign language rather than using it. An overwhelming majority of the trainees use their mother tongue as the language of instruction (e.g. when addressing the learners, managing them, when explaining instructions to exercises and tasks, etc.) and as a tool for making meaning clear. Unknown vocabulary items, example grammar sentences, and even whole texts are translated from English into Polish and the other way around. Cues and prompts are issued in L1, picture flashcards are described in Polish, and learners' L1 responses are acceptable or even welcome. When asked to justify their overuse of L1, the trainees do admit it is better to avoid it as it helps the learners think in L2, but claim that they are afraid the students will not understand them and so not pay attention. Although the trainees are familiarized with other ways of making meaning clear at the very beginning of methodology classes, they seem to stick to the misconception that explaining equals translating and that translation is the basic and most effective learning and teaching strategy. Being based on the trainees' own experiences at school, these beliefs are firmly stuck and really difficult to eradicate.

Another global problem which can be observed in nearly every classroom is the trainees'failure to activate the learners. Again, this aspect of teaching is emphasized by the author very early on and her students do seem to be convinced that only if actively involved in discovering information, do pupils benefit from classroom instruction. Still, while teaching, the trainees tend to "play God", giving all the information and answering their own questions. They rarely elicit from their learners, and even if they try to do so, they are often too impatient to wait for the answer. To account for this attitude, the trainees complain of school lessons being too 
short to allow more elicitation or of students getting frustrated if their responses are not accurate. Bearing in mind the value of discovery learning, the above obstacles surely could be more frequently ignored.

In fact, being accurate, exact, and thorough seem the necessary features of a good language teacher. The trainees will go to great lengths to be $a b-$ solutely correct not only in grammar, vocabulary, spelling, but primarily in pronunciation. And they will, unfortunately, require the same from their pupils. For example, when talking about food and eating, one of the trainees introduced the word dessert. She then remembered the difficulty she herself must have experienced with the minimal pair dessert - desert and hurriedly drew the learners' attention to the pronunciation problem. Although some brighter students may have found this information intriguing, the group in question (which the trainee knew very well) got totally confused by the irrelevance of the teacher's explanation (even though it was provided in L1). When covering grammar structures, the trainees seem to be satisfied only if all the exceptions to the rule have been given, and when they are not sure how to spell a word or how to say something in English, they really get embarrassed and feel they have lost face. This kind of behavior probably stems from the trainees' university experience. Because their teachers require them to exhibit proficiency and high accuracy in the foreign language, the students believe their own pupils can only learn from absolutely correct, exact, and exhaustive models. While being both accurate and fluent are undeniably the necessary prerequisites of a good language teacher, emphasizing correctness and intellectualizing the process of teaching/learning can often act to the detriment of language learners. After all, an average school pupil is learning English for communicative rather than academic purposes.

\subsection{Example specific problems}

The present section contains a list of example specific problems the trainees often struggle with in the classroom. Each situation was observed on at least two occasions.

Teaching receptive skills:

- asking the learners to read or listen to the text and not giving them any task before;

- giving the learners a comprehension task that does not check comprehension (because it repeats the wording and structures from the text and thus is too easy);

- having the learners read a text to do a comprehension task, and once they finish, asking them to list new or difficult vocabulary items before checking their answers to the comprehension questions; 
- having the learners read the text aloud sentence by sentence in order to do a comprehension task.

- Teaching productive skills:

- giving the learners only practice tasks and hardly ever truly communicative tasks;

- immediately correcting almost all the learners' errors while they are speaking,

- giving the learners only form feedback (rather than content feedback) after they finish speaking;

- having the learners write something rather than, or before, saying something;

- correcting every error in the learners' written compositions.

- Teaching grammar:

- presenting grammar structures out of context;

- practicing the new structure only in written exercises and rarely spoken tasks;

- stating the rule rather than leading the learners to discover it.

- Teaching vocabulary:

- presenting, practicing, and testing vocabulary with one technique, i.e. translation;

- presenting new words but not practicing them;

- presenting too many new items in one lesson and expecting the learners to know all of them actively.

\section{THE SURVEY}

As stated above, the question that has been worrying the author for a few years now is why, despite so many methodology classes at the university and so much exposure to the real classroom situation, the student trainees do not transfer the skills and knowledge to their teaching. Based on her experience, the researcher hypothesized that the reason for such a situation could stem from the students' attitude to the methodology course. The trainees may believe that once they know the language, they also know how to teach it, and, therefore, special training devoted to it is not really necessary. In other words, even if they do learn new approaches to and principles of teaching, they do not consider them useful or relevant and tend to stick to their own ideas about language learning/ teaching which are often solely based on their experience as learners. And such comments as "What we are discussing here is pure theory: no teacher behaves in this way." "None of my teachers ever applied any of the methodology we are learning." or "Do you mean we've been taught in a totally wrong way?" indicate how differ- 
ent the trainees' experience is from what they learn in the methodology class.

How do the students perceive the methodology course they have to take? What are their attitudes to teacher training practice? The answers to the above and other related questions were found in the questionnaire designed by the author.

\subsection{The respondents and the questionnaire}

The questionnaire was distributed among 17 third-year School of English students (all the author's methodology students in the academic year 2003/2004), who had just finished their methodology course and had completed their teacher training practice. All of them received credit for the course and for the teaching practice so, hopefully, their answers were not biased in any way. They were not required to sign their questionnaires.

The questionnaire consisted of 8 questions, which, to make the procedure easier for the respondents, were partly open- and partly close-ended (see Appendix). That is, in the majority of the questions the students chose one of the provided answers but were also able to write a response of their own.

\subsection{The results of the questionnaire}

The tables ( 1 and 2 ) below show the respondents' attitudes to the methodology classes b e f o r e (question 1) and a f t e r (question 3 ) the course ${ }^{1}$.

Table 1. The trainees' attitudes to ELT methodology b e fore the course

\begin{tabular}{|l|c|}
\hline \multicolumn{1}{|c|}{ Attitude } & Number of students \\
\hline Positive attitude & $8(47 \%)$ \\
Negative attitude & $2(11.8 \%)$ \\
Neutral attitude & $7(41.2 \%)$ \\
\hline
\end{tabular}

Table 2. The trainees' attitudes to ELT methodology a $\mathrm{f}$ e $\mathrm{r}$ the course

\begin{tabular}{|l|c|}
\hline \multicolumn{1}{|c|}{ Attitude } & Number of students \\
\hline Positive attitude & $16(94.1 \%)$ \\
Negative attitude & 0 \\
Don't know & $1(5.9 \%)$ \\
\hline
\end{tabular}

The above results seem to only partly support the researcher's hypothesis. While about a half of the students claim they welcomed the idea of learning how to teach English, only 2 expressed a definite negative opinion of it and 7 had neither a positive nor a negative attitude. It is interesting to note some of the justifications that the informants gave for their answers (Table 3 ).

${ }^{1}$ Although the study was carried out on a small group of respondents, the tables contain both numbers and percentages, which should facilitate comparing the results. 
Table 3. The trainees' justifications for their attitudes to ELT methodology b e f o $\mathrm{e}$ the course

\begin{tabular}{|l|l|}
\hline \multicolumn{1}{|c|}{ Attitude } & \multicolumn{1}{c|}{ Comment } \\
\hline Negative & I thought the knowledge from this class would not be useful for me. \\
\hline Positive & $\begin{array}{l}\text { I wondered if my expectations about the difficulty of being a teacher would } \\
\text { turn out to be true. } \\
\text { It was obvious to me that knowing a language does not mean knowing how to } \\
\text { teach it. }\end{array}$ \\
\hline Neutral & $\begin{array}{l}\text { I had a neutral attitude but wondered how it would be possible to talk about } \\
\text { such obvious matters for three semesters. }\end{array}$ \\
\hline
\end{tabular}

It is not then true that all trainees begin their methodology instruction with a negative attitude, which could in turn affect the results of their study and their performance as teachers.

The respondents' answers to question 3 (Table 2) are even more optimistic. Irrespective of the students' initial approach to the course, almost all of them admit they have benefited from it. Only one person (who expressed a positive opinion in question 1) claims he/she will be able to answer this question when he/she has applied the knowledge from the course in his/her own teaching. Quite the contrary, other students say that they do implement the techniques and principles they have learned and they can see these techniques bring good results. One person admits that thanks to the course, he/she has come to respect teachers and teaching and developed a critical attitude to his/her teachers and to him-/herself as a teacher.

The students' responses to the above question are very strongly supported by the numerous examples they give in question 2. Although the trainees did not revise the material right before filling in the questionnaire, they were able to provide so many various techniques and rules that, if collected, they could form useful and fairly complete guidelines for beginning teachers. Most of the respondents wrote more than one example for every area, and there was only one person who did not write any examples, claiming he/she could not remember any. Table 4 below lists some of the learners' responses.

Table 4. Example language teaching techniques and principles provided by the trainees

\begin{tabular}{|l|c|}
\hline \multicolumn{1}{|c|}{ Example technique or principle } & $\begin{array}{c}\text { Number of } \\
\text { students }\end{array}$ \\
\hline \multicolumn{1}{|c|}{} & \multicolumn{1}{|c|}{2} \\
\hline Give the learners a task before they read or listen to a text & $6(35.3 \%)$ \\
Don't give the learners too easy comprehension tasks & $1(5.9 \%)$ \\
Elicit the meaning of words from the learners rather than provide it yourself & $2(11.8 \%)$ \\
Don't have the learners read the text aloud individually (it can be embarrassing) & $1(5.9 \%)$ \\
Don't interrupt the learners while they are speaking; let them finish and correct & $6(35.3 \%)$ \\
$\quad$ later & $4(23.5 \%)$ \\
\hline
\end{tabular}




\begin{tabular}{|l|l|}
\hline \multicolumn{1}{|c|}{ 1 } & \multicolumn{1}{|c|}{2} \\
\hline Always give positive feedback & $6(35.3 \%)$ \\
Don't correct all the errors in the learners' written compositions & $5(29.4 \%)$ \\
Present new grammatical structures in context & $4(23.5 \%)$ \\
Explicit and deductive grammar teaching are not the only ways to teach lan- & $8(47 \%)$ \\
$\quad$ guage structures & $4(23.5 \%)$ \\
There are a lot of techniques of vocabulary teaching & $2(11.8 \%)$ \\
Translation is not always an effective vocabulary teaching technique & $6(35.3 \%)$ \\
Teach a limited number of vocabulary items (about 7) in one lesson &
\end{tabular}

The above items were not randomly chosen by the author. It is interesting to note how well they correspond to the list of example specific problems in section 3.2. It can be concluded then that after the methodology course, the trainees are well aware of the appropriate teaching techniques. They may even be more conscious of those principles that run counter to their established ideas of teaching. In other words, the reason why many of the students do not apply proper ways of teaching is not because they do not know or remember them or because they think these techniques are useless. As the answers to questions 2 and 3 indicate, the trainees generally appreciate what they have learned in their methodology classes.

Questions 4 and 6 were aimed at finding out about the students' plans for the future as regards teaching. Moreover, the researcher wanted to know whether the experience of observing other teachers at school and of teaching itself had to any degree influenced the trainees' attitudes to the teaching profession. Tables 5 and 6 show the trainees' answers to these two questions.

Table 5. The trainees' attitudes to the teaching career b e f ore the teacher training practice

\begin{tabular}{|l|l|}
\hline \multicolumn{1}{|c|}{ Question } & Number of students \\
\hline Want to be teachers? & $2(11.8 \%)$ \\
Don't want to be & $5(29.4 \%)$ \\
teachers? & $10(58.8 \%)$ \\
Are you sure? & \\
\hline
\end{tabular}

Table 6. The trainees' attitudes to the teaching career a $\mathrm{t}$ e $\mathrm{r}$ the teacher training practice

\begin{tabular}{|l|l|}
\hline \multicolumn{1}{|c|}{ Question } & Number of students \\
\hline Want to be teachers? & $2(11.8 \%)$ \\
Don't want to be & $6(35.3 \%)$ \\
teachers? & $9(52.9 \%)$ \\
Are you sure? & 9 \\
\hline
\end{tabular}

As can be inferred from the tables, the teacher training practice has had very little influence over the students' attitudes: only one respondent had changed his/her view (from not being sure about the future as a teacher to not wanting to be a teacher). However, what the above figures also show is that out of 17 trainees only 2 (the same students in both questions) actually want to teach. It is important to notice too that among the 9 respondents who are not sure quite a few would like to avoid teaching if they can but are realistic about their prospects for the future. In other words, they believe they will end up as teachers rather than translators or interpreters. 
Although the teaching profession appears to be so unpopular, paradoxically, half of the students in question (see table 7) generally approved of the idea of having practice at school despite their busy schedules in the third year.

Table 7. The trainees' attitudes to teacher training practice

\begin{tabular}{|l|c|}
\hline \multicolumn{1}{|c|}{ Attitude } & Number of students \\
\hline Positive attitude & $9(32.9 \%)$ \\
Negative attitude & $7(41.2 \%)$ \\
Not sure & $1(5.9 \%)$ \\
\hline
\end{tabular}

Still, when asked where they have learned more about language teaching: on the university methodology course or while doing their observations and teaching at schools, fewer respondents point to the school (table 8).

Table 8. The sources of the trainees' skills and knowledge of teaching

\begin{tabular}{|l|c|}
\hline \multicolumn{1}{|c|}{ The trainees learned } & Number of students \\
\hline $90 \%$ on the course and $10 \%$ at school & $1(5.9 \%)$ \\
$70 \%$ on the course and $30 \%$ at school & $7(41.2 \%)$ \\
$50 \%$ on the course and $50 \%$ at school & $5(29.4 \%)$ \\
$30 \%$ on the course and $70 \%$ at school & $4(23.5 \%)$ \\
\hline
\end{tabular}

If the students generally admit that they do profit from the methodology classes, then why don't they actively use the information in their teaching? Part of the answer seems to come from the trainees' responses to the last question.

In question 8 the informants were required to comment on any aspect of the whole methodology program (including both the university classes, though not the lectures, and practice at schools) and list the elements that were missing, that they liked etc. As is often the case, the students differed in their evaluation of the various aspects of the program. Hence, while some of them liked the discussion of the material that they read for a given lesson, others claimed there was too much of it. Some wanted more opportunities to answer their individual questions (concerning their teaching experience) and more evaluation of different techniques and tasks, whereas others were fed up with discussing individual cases and would have liked less evaluation. However, what quite a few respondents seemed to agree on is the nature and aim of the methodology course and presumably its striking opposition to what is happening at school. Table 9 summarizes the most common responses. 
Table 9. The trainees' evaluation of the methodology course

\begin{tabular}{|l|c|}
\hline \multicolumn{1}{|c|}{ Example comments } & Number of students \\
\hline $\begin{array}{l}\text { What was missing in the methodology classes was referring what we were } \\
\text { learning to a real classroom situation }\end{array}$ & $3(17.6 \%)$ \\
$\begin{array}{l}\text { We talked about the ideal, and not the real classroom } \\
\text { There was too much theory and pure facts which may have little to do with } \\
\text { reality }\end{array}$ & $3(17.6 \%)$ \\
$\begin{array}{l}\text { I liked the exercises that showed us how to implement the theory we were } \\
\text { learning in the classroom }\end{array}$ & $5(29.4 \%)$ \\
\end{tabular}

Although the last response in Table 9 seems different from the others, or at least it seems more favorable to the teacher, in fact all the answers carry the same idea that methodology classes are about th e or y! In other words, no matter how many exercises or tasks are done, and no matter how much micro-teaching is carried out, the course itself is still perceived as theoretical. The students admit, therefore, they are learning knowledge in the classes, but they probably do not feel they are learning s k ills.

\section{CONCLUSIONS AND RECOMMENDATIONS}

Although the study described above was conducted on a relatively small group of respondents, it allows one to draw certain conclusions about the trainees' approach to ELT methodology learning and helps answer the question why they often fail to transfer the knowledge and skills from the methodology classes to their teaching.

First of all, the students are generally not against the idea of studying methodology and participating in teacher training practice. Having completed the course, a vast majority of them perceive it as necessary and beneficial and prove to have learned a lot by giving plenty of examples of useful teaching techniques. The bad news is, however, that so few of the trainees see themselves as future language teachers. And just because they are not really planning to work at schools, they may not feel the need to try out the techniques and principles they have acquired. Furthermore, as they describe the methodology course as "theoretical", they might be reluctant to transfer this "theory" to their classrooms and prefer to implement the "practice" they know from their own learning experience 2 . Unfortunately, this "practice" still seems to be based on translation, teacher dominance, and learner de-

${ }^{2}$ Part of this "practice" constitutes the observations the trainees do before they start teaching. Because schools are frequently crowded with trainees, it can sometimes be very difficult to be accepted by a school, and students end up observing various instructors, and not necessarily those that should be recommended as models for a novice teacher. 
pendence. Finally, the knowledge they have appears irrelevant once they face a class of 20 undisciplined and presumably unmotivated teenagers. Experimenting with new approaches and tasks they learned about in "ideal" conditions may be seen as hardly possible.

What action should the methodology instructor take in order to ensure more successful transfer? Speaking very generally, he/she should try to make the course more "practical" by, for example, ignoring the students' complaints and having them do a lot of micro-teaching tasks. At the same time, whatever exercise they do, the instructor should make sure it is set in a very specific context. For instance, the task:

Design a sequence of activities for introducing the Past Continuous tense to intermediate learners.

could be made less general by adding the following information:

Your students have problems understanding the grammar terms in L2 and tend to use a lot of L1 in the classroom; (their former English teacher did not mind it, but you believe L1 should be avoided whenever possible); they are generally passive when learning new grammar structures and you would like to activate them; they dislike writing grammar exercises and can be very disruptive while doing them; they like games and visual aids.

Such an instruction would definitely make the whole situation less "ideal" and would require the trainees to think of solutions to a number of common problems.

It is vital to provide a more direct link between what the trainees are learning on the methodology course and what they are teaching at schools. The students can be asked to focus on particular aspects of language skills or components, implement a given technique they have learned, and then report back their observations and feelings. For example, they may receive the following task:

Select a reading text you want to introduce in your lesson. Choose a few key words and pre-teach them avoiding $L 1$ (whenever possible). Present a comprehension task explaining only if absolutely necessary and avoiding L1. Have the learners read the text silently to do the comprehension exercise. Check their answers never accepting any response in L1. Reflect on the experience by answering the questions:

Were the students able to understand you?

How much L1 did you have to use?

How much L2 did the students use?

Were the students able to answer the comprehension questions?

Were the students ever able to infer meaning? 
An inherent difficulty of the above procedure may stem from the fact that the trainees are often supposed to cover the material that the supervising teacher at school assigns them. In such a case, the students themselves should be allowed to choose the task or technique they want to try out and evaluate, taking into account the material they have to use. In fact, they may be required to regularly reflect on their teaching by writing short diary entries. For instance, they could be asked to do the following task every week or fortnight:

Select a teaching technique, principle or task you have recently learned and would like to test in your own teaching. Plan an activity or activities for your group of learners and in your diary write down your expectations, fears, doubts, etc. about the new technique. Implement the technique carefully observing your students and then take down your evaluation of it in the diary. Be ready to report your observations in our class.

The above examples clearly point to reflection as the possible solution to the problem of transferring knowledge of methodology to actual teaching. While the value of constant reflection in teaching and its vital role in teacher development cannot be overestimated, it seems even more indispensable in teacher training (cf. Wallace 1991). Obviously, giving the trainees such tasks will mean spending precious class time on their reports rather than covering new material. However, considering the undeniable role conscious reflection plays in turning theory into practice, devoting time to it at the expense of learning more "pure theory" is definitely worthwhile.

\section{APPENDIX}

\section{Questionnaire for trainees}

The aim of the following questionnaire is to find out how the trainees evaluate the methodology classes (not the lectures!) and teacher training practice. Please answer the questions by giving as complete answers as you can.

1. At the beginning of the methodology course you had (tick one answer and/ or write your own in the space provided)

a) a positive attitude to it: you are going to learn how to teach a foreign language

b) a negative attitude: you know the language pretty well and you are an experienced language learner, so special classes devoted to learning how to teach don't seem necessary

c) a neutral attitude: methodology is yet another course you need a credit for, so you are going to attend it and do your homework, but you don't really expect you'll benefit from it

d) other: 
2. Give an example of at least one piece of information that you remember from your methodology classes (it should be something new you have learned and possibly are going to apply in your own teaching) related to:

- using teaching aids

- teaching receptive skills

- teaching writing

- teaching oral communication

- error correction and feedback

- teaching vocabulary

- teaching grammar

- other aspects

3. Now that the methodology course is over, you believe (tick one answer and/or write your own in the space provided)
a) it was necessary and useful; you learned a lot
b) you didn't really learn anything new
c) other:

4. Before the teacher training practice at school (tick one answer and/or write your own in the space provided)
a) you wanted to be a teacher
b) you definitely did not want to be a teacher
c) you were not sure

5. Before the teacher training practice at school you had (tick one answer and/or write your own in the space provided)
a) a positive attitude to it: you wanted to see what teaching is all about
b) a negative attitude: you had no time for spending hours at school
c) other:

6. Now that the teacher training practice it over (tick one answer and/or write your own in the space provided)
a) you want to teach
b) you are positive you will not be a teacher
c) you are considering a teaching career
d) other:

7. If all your knowledge and skills related to foreign language teaching constitutes $100 \%$, then you learned (tick one answer and/ or write your own in the space provided)
a) $50 \%$ from the methodology classes and $50 \%$ from the teacher training practice
b) $70 \%$ from the methodology classes and $30 \%$ from the teacher training practice
c) $30 \%$ from the methodology classes and $70 \%$ from the teacher training practice
d) $0 \%$ from the methodology classes and $100 \%$ from the teacher training practice
e) $100 \%$ from the methodology classes and $0 \%$ from the teacher training practice
f) other:

8. Please write down any other comments and your feelings and reflections about the methodology program (e.g. what was missing in it, what you liked about it, etc.).

\section{REFERENCES}

Wallace, M.J., 1991. Training foreign language teachers. A reflective approach. Cambridge: CUP. 